\title{
Research of Influence of Multimedia Technology Application Aid on Music Education
}

\author{
Ya-Lin ZHANG \\ College of Arts and Communications, Bohai University \\ zhangyalin_zyl@163.com
}

Keywords: Multimedia technology, music education, learning efficiency.

\begin{abstract}
Multimedia technology has the most prominent advantage of providing music teaching with convenient audio-visual conditions. It complies with research and development of music education application software in various schools and courses, which will be key link of applying multimedia technology in music education. Multimedia technology is regarded as an aided teaching means for analyzing the form and significance of integrating it into ordinary university music education. Precautions in concrete teaching practice link are proposed. Effective methods and approaches are provided for improving music teaching effect of ordinary universities comprehensively. The author always considers the effect and influence of computer multimedia technology on music education. He believes that computer multimedia technology has comprehensive influence on music education at both theory level and operation level. Our thinking mode is changed on one hand, and our operation method is also changed on the other hand.
\end{abstract}

\section{Introduction:}

Computer and digital technology are used in music for less than 30 years widely all over the world, which were at the exploration stage [1-3] in the past. Multimedia technology has become the most important modern high-tech means at present, which has been penetrated into all fields of our study, work and life. Its application is backward relatively in the aspect of China music education. The phenomenon is caused by reasons in many aspects: computer and corresponding equipment have lower coverage in music teaching units. Music education is lack of application software. Few teachers can use the technology, etc. [4]. In 'ordinary university music education' teaching under the so-called multimedia aided teaching, the high-tech means computer is combined with ordinary university music education, a better music learning environment is created for college students, thereby college students not majoring in music can integrate music, words, image, animation, video data, etc. during learning music knowledge at ordinary universities. Better learning effect can be achieved through sensory stimulation in auditory, visual, and many other aspects [5-6]. Therefore, the superiority of applying multimedia technology in music education and to-be-solved key links should be analyzed initially in the paper, and some preliminary implementation ideas are proposed [7].

\section{Influence of Modern Technology on Music Teaching Contents}

Traditional music teaching contents are old-fashioned relatively. Students achieve poor learning effect. Since traditional music teaching contents have too large coverage, students have less understanding on modern and contemporary music knowledge and relevant dynamic trends. Students need to learn music knowledge closely related to modern technology in music teaching urgently. However, the knowledge cannot be timely reflected in teaching contents, which is not beneficial for music development extremely. We should add modern music knowledge timely, therefore knowledge structure of students can keep up to times. Modern technology has been used in the field of music widely. All majors of music are affected by modern technology more and more widely with quiet changes. For example, new disciplines appear such as sound director, music composition, etc. However, the change is rarely embodied in our music teaching contents. The teaching contents are too old-fashioned according to textbook of music education major. Music 
composition is cited, music composition is the most advanced in many disciplines of music. It is most sensitive to modern technology and idea. Even so, our teaching contents are updated too slowly aiming at the most contemporary discipline. The analyzed and interpreted works still contain Bach and Handel in the baroque era to Shostakovich and Pendergrass in 1950s and 1960s, etc. The consequent works are rarely known. Teaching was blank for 40 years from 1950s and 1960s to present. The duration of 40 years is quite important.

\section{Superiority of Applying Multimedia Technology in Music Education}

Multimedia technology has basic characteristics as follows: word, sound, image, animation and other media information are integrated together under the control of computer, digital technology and human-computer interaction processing ability are utilized for realizing communication of information, and development of information superhighway and international Internet, and multimedia technology is further assisted. Multimedia technology has the most prominent advantage that audio-visual conditions are provided for music teaching. Audio-visual advantages are divided into follows basically: audible range is wide, including own playing and singing, playing of CD, VCD and self-composed music, etc; tone color is rich and diversified. Various independent and comprehensive tone colors can be adopted; users can manipulate and call own desired sound freely according to man-computer interaction. Real-time recording function is available, users can record sound at any time on one hand, record can be segmented on the other hand, and they can be synthesized for playing. More importantly, auditory and visual contents are displayed at the same time. The rich media stimulation must bring great fun to teaching and learning inevitably, and teaching efficiency can be improved greatly.

\section{Diversifying Teaching Means}

Psychology shows that learning interest aims at reaching good teaching effect. It is the inner drive for promoting people's thirst for knowledge. The multimedia aided teaching has the most prominent advantage that too excessive information is solved in traditional music teaching. Extracted information contents are converted into concrete form in concrete, vivid and lifelike virtual scene, which are presented to students. Therefore students can comprehend and memorize more easily in the learning process, and the teaching objectives can be realized easily in the pleasant learning process.

\section{Facilitating Individualized Teaching}

Music education of college students not majoring in music at ordinary university has particularity compared with professional music education, especially its particularity in the aspect of teaching object. If music teacher can use multimedia for aided teaching properly, multimedia courseware or some music knowledge background can be combined with related knowledge of other disciplines for presenting multimedia. Counter-productive teaching effect can be received. The following requirements of classroom teaching can be met effectively in the teaching mode, such as large capacity, wide information and high efficiency. Teachers' blackboard writing time can be saved, and the capacity of information can be increased on one hand, abstract text materials can be presented to students systematically, visually and concretely on the other hand in the aspect of classroom knowledge interpretation. Classroom teaching contents are enriched greatly on one hand; classroom space can be left to students really on the other hand. Students can feed back information timely during learning at the same time, thereby better mobilizing their enthusiasm and initiative of learning.

\section{Facilitating Sufficient Utilization of Network Resources, and Improving Learning Efficiency}

Application of multimedia technology and network resources in music education of colleges and universities is embodied on classroom teaching on one hand; teaching classroom can be extended to extra-curricular multimedia aided teaching on the other hand. Students can make use of multimedia 
technology and network resources to learn music knowledge, and appreciate music works. Good music learning environment is created for students by rich and diversified network resources and good visual and sound effects, thereby arousing students' interest in learning music, and improving their enthusiasm to participate in music teaching actively. Currently, college students can use network resources freely, and technical support is provided for multimedia aided music teaching.

\section{Key Link of Applying Multimedia Technology in Music Education}

Currently, some universities, and many elementary and middle schools already have the hardware conditions of utilizing multimedia technology in music teaching in China. More schools are also preparing to set up corresponding facilities. However, computer hardware facilities are not 'bottlenecks' to restrict application of multimedia technology in music education. The 'bottleneck' is perfection of teaching software. It is understood that researchers in many international universities and research institutions have applied multimedia technology in music education as their research project. Many software companies develop and produce music education software specially, and even many music teachers are compiling teaching software. It is obvious that research and development of music education application software in line with various schools and courses will be key links to apply multimedia technology in music education.

China music education can be divided into three levels roughly according to different education purposes and objects: professional music education for cultivating music workers and music teachers; music education of regular primary and secondary schools and popular music education at popularization level. The three levels can be used as basis for studying music education software. Professional music education software development should be targeted to different courses directly. Different software can be developed for different courses specially, which should become guiding ideology for introducing and developing professional music education software.

\section{Application of Modern Technology Means in Music Education}

Teaching means diversification is the education mode which is pursued by all education workers. Advantage of modern multimedia technology can be displayed more sufficiently in teaching will no doubt since it is necessary to utilize sound function in music education. Teachers often carry tape recorder, tape and other heavy equipment to classroom in traditional teaching. Simple equipment cannot guarantee the classroom efficiency, good audio and sound quality. Many music works can be played according to music sound function of multimedia technology, which can be displayed with text, graphics, pictures and video synchronously. Therefore, teachers should produce teaching courseware before class; necessary music notes and sound in the classroom are edited and composed according to teaching requirements through software. Modern teaching equipment can be utilized in the classroom for explanation with texts and pictures leisurely, and music can be played.

However, the method only can be used for theory class at present; music education has the specific problem of professional course modernization, which is not solved better, such as vocal music teaching. Vocal music is a very individual discipline. It is difficult to judge by a unified standard. In addition, many people attend class synchronously. Sounds are easily interfered with each other. Therefore, traditional vocal music teaching has always been a teaching mode for teachers in front of students. The mode has exposed the disadvantages of low efficiency fully, which has become a bottleneck for modernization reform of music education. Some schools simply change the professional teaching into a mode that one teacher teaches four or five students in order to expand the teaching scope. Though the education scope is expanded, education cost is lowered, and teaching quality cannot be improved.

\section{Facilitating Sufficient Utilization of Network Resources, and Improving the Learning Efficiency}

Application of multimedia technology and network resources in music education of colleges and 
universities is embodied on classroom teaching on one hand; teaching classroom can be extended to extra-curricular multimedia aided teaching on the other hand. Students can make use of multimedia technology and network resources to learn music knowledge, and appreciate music works. Good music learning environment is created for students by rich and diversified network resources and good visual and sound effects, thereby arousing students' interest in learning music, and improving their enthusiasm to participate in music teaching actively. Currently, college students can use network resources freely, and technical support is provided for multimedia aided music teaching. For example, generation historical and cultural background, and other information about the works appreciated at classroom can be sorted and collected by students before class through network, thereby strengthening students' memory, and improving their learning initiative. In addition, if conditions are available, a BBS can be set on Internet aiming at music appreciation courses, thereby encouraging students to participate in discussions, expanding the areas of thinking, learning to evaluate music, and cultivating their creative thinking.

\section{Implementation Plan of Applying Multimedia Technology in Music Education}

Concrete implementation of applying multimedia technology in music education can be divided into the following aspects:

Computer music classroom is established gradually in universities. In the future, the schools are equipped with multimedia equipment. It must become a major trend. Computer music can be used synchronously with other disciplines completely. A multi-unit classroom can be established in schools with sufficient conditions, more audio and video equipment can be equipped for teachers, and the teaching effect is more ideal. (2) A research team is established, which is guided by teaching reform breakthrough and scientific research, wherein music education workers are combined with computer experts. As the above-mentioned contents, multimedia technology is applied in music education; it is not a problem which can be solved through purchasing some equipment. A group of people should be committed to the research of the key link and introduce new achievement constantly. Education competent departments, schools and scientific research units, can give corresponding support. The development of the career can be actually guaranteed. (3) Teacher training can be organized. People using equipment and applicable software become the most important determinants. Teaches can be trained gradually from point to surface. Currently, some schools have obtained certain achievements and accumulated experience in the established computer music lab. The labs can be regarded as foundation for developing from training of backbone teachers to wider scope. In training, participation by scientific research personnel and software compilation personnel is very important since software quality can be higher and higher in two-way exchange. It is worth mentioning that multimedia technology application is not complicated in fact, and students can become experts completely through mastering it and learning it constantly in application.

\section{Compliance with Teaching Rules, and Reasonable Arrangement of Teaching Contents}

First of all, teachers should formulate suitable teaching plan, and pay attention to the systematic, organized, and logical features thereof according to music quality of education objects at different levels due to the particularity of music education teaching objects in colleges and universities. Secondly, teachers should arrange teaching activities timely and rationally according to actual teaching effect in the teaching process. Thirdly, teachers should formulate teaching objectives of each foundation teaching link according to teaching plan, and classroom can be designed rationally. There are both arts students and science students in ordinary university music classroom. There are both students majoring in literature and historiography, and students majoring in machinery and chemical industry. There are both students accepting music education since childhood, and students who cannot read music notes. How to design and arrange teaching contents, and master teaching process have become keys in evaluating success of music classroom teaching in colleges and universities aiming at music knowledge structure with complicated teaching objects. In teaching, if 
the differences of students' knowledge structures can be utilized well for designing teaching carefully, it not only can promote college students to learn music knowledge, but also can make students to comprehend music knowledge as deeply and widely as possible within short teaching time through intersection among disciplines, thereby learning music knowledge, deepening understanding on music and related cultures, and realizing the education objectives of shaping students by art education in schools finally.

\section{Conclusion}

Multimedia aided teaching becomes an inevitable trend in the development of modern education due to advantages in many aspects. However, application of multimedia technology only can play an auxiliary role in ordinary university music classroom currently. It can be used on the basis of following teaching principles. The leading role of teachers and the principal role of students can be exerted fully. The application 'degree' can be mastered correctly, thereby promoting teaching, and improving the teaching efficiency. The practice of ordinary university music education teaching proves that implementation of music education on college students not majoring in music in colleges and universities plays an important role to cultivate good learning habits of college students, improve comprehensive quality, and establish positive and healthy outlook on life and world view. Solid material and technology guarantee is provided for developing ordinary university music education in the future without doubts by exploration of ordinary university music teaching mode, especially application of advanced education science and technology means, such as multimedia aided teaching and other means. Ordinary university music education has better prospect in the future.

\section{References}

[1] Gong Wenli. On application of multimedia in the ordinary university music teaching [J]. China Adult Education, 2009, (8);

[2] Zhang Dongmei. Rational application of multimedia in solfeggio and ear training teaching [J]. National Music, 2010, (3);

[3] Song Chenggui. Application of modern education technology solfeggio and ear training teaching [J]. Jilin Education, 2010, (3);

[4] XiaoYu. Application of multimedia technology in college music teaching [J]. Journal of Kaifeng Institute of Education, 2014, (01);

[5] Li Haiyan, Analysis on applying multimedia technology in college music teaching [J]. Music Time and Space, 2014, (9);

[6] Sun Ting. Effective application of multimedia teaching technology in music teaching [J]. Education Technology and Equipment in China, 2013, (22);

[7] Yang Rui. Discussion of applying multimedia technology in music education teaching of higher normal universities [J]. Instrument, 2011, (5); 